\title{
Teaching "Human Rights in Africa" Transnationally: Reflections on the Jos-Osgoode Virtual Classroom Experience
}

Obiora Chinedu Okafor

Osgoode Hall Law School of York University, ookafor@osgoode.yorku.ca

Dakas C. J. Dakas

Source Publication:

German Law Journal. Volume 10, Issues 6/7 (2009), p. 959-968.

Follow this and additional works at: https://digitalcommons.osgoode.yorku.ca/scholarly_works (c) $(i) \Theta(9$

This work is licensed under a Creative Commons Attribution-Noncommercial-No Derivative Works 4.0 License.

\section{Recommended Citation}

Okafor, Obiora Chinedu, and Dakas C. J. Dakas. "Teaching "Human Rights in Africa" Transnationally: Reflections on the Jos-Osgoode Virtual Classroom Experience." German Law Journal 10.6/7 (2009): 959-968. 


\title{
SPECIAL ISSUE: TRANSNATIONALIZING LEGAL EDUCATION
}

\section{Teaching "Human Rights in Africa" Transnationally: Reflections on the Jos-Osgoode Virtual Classroom Experience}

\author{
By Obiora Chinedu Okafor ${ }^{*}$ and Dakas C.J. Dakas ${ }^{* *}$
}

\section{A. Project Description}

During the Fall of 2007, as part of a much broader York-Nigerian Universities linkage project that he had been working on for some time, Professor Okafor taught an internationalized version of a pre-existing existing course entitled "Human Rights in Africa." At the same time, Professor Dakas of the Faculty of Law, University of Jos, Nigeria (assisted by Mr. J.D. Gamaliel) taught a similarly modified version of an existing course at their own institution. Professor Dakas, a former Hauser Global Scholar at New York University and most recently the attorney-general of the Plateau State of Nigeria) was the lead faculty at that partner law school in Nigeria.

Both courses were linked and connected to each other over the internet, almost always in real time. This pedagogic linkage was achieved through collaborative development with the partner faculty of a virtual transnational classroom (created via the use of cutting edge

\footnotetext{
* Professor, Osgoode Hall Law School, York University, Toronto, Canada; and Canadian Project Director of the emerging York-Nigerian Human Rights Education and Research (NIHERNET) Project of which this transnational classroom project is a part. Email: ookafor@yorku.ca.

${ }^{* *}$ Associate Professor/Reader and Ag. Head of the Department of Private Law, Faculty of Law, University of Jos; Visiting Professor of International Human Rights Law at Osgoode (Fall 2007); and former Honorable AttorneyGeneral and Commissioner for Justice of the Plateau State of Nigeria.Email: dakasdakas@yahoo.com

We wish to express our immense gratitude to the following York University faculty: Vice President (Academic) Sheila Embleton, Associate Vice President (International) Adrian Schubert, Associate Vice President (Research Social Sciences) David Dewitt, Osgoode Dean Patrick Monahan, Associate Dean Robert Wai, and Associate Dean Peer Zumbansen (for generous internationalization, incentive, CLPE, and other grants/funding that enabled us to construct and use this virtual transnational classroom). We also wish to express our immense gratitude to the following University of Jos faculty: Vice Chancellor Sonni Gwanle Tyoden, Deputy Vice-Chancellor (Academic) Bethrand Nwufo, Faculty of Law Dean, Professor Jamila M. Nasir and Mr. J.D. Gamaliel (for their financial, pedagogic and other support without which the project would not have been possible). Kurt Binnie, Osgoode's Director of IT services, deserves special thanks for his extraordinary creativity, industry, support, and good cheer; and so does Mrs Abiola Omo-Tom-Fregene, the Director of the Computing Centre of the University of Jos. The IT staff at the University of Jos (especially Tizhe Zira and Emmanuel George), and at Osgoode Hall Law School (especially Gautam Janardhanan and Nyree Mahadeo) also deserve our immense gratitude for their tireless efforts which ensured the success of the project. Opeoluwa Ogundokun's excellent research and pedagogic assistance is gratefully acknowledged.
} 
information technology (IT) solutions) which served as a key mode of interfacing and delivering the two separate but closely connected partner courses. In order to fully form this transnational classroom, class instruction and discussion were supplemented and complemented by web-based real-time video-conferencing (and to a lesser extent, in practice, by a discussion board). As a result, students both at Osgoode/York and the University of Jos (hereafter Jos), for the most part, had access to and learned within one integrated, if virtual, space.

In one sense, three separate pedagogic spaces were created and interfaced: the regular classroom in Jos (which sometimes met outside the joint Jos-Osgoode sessions), the regular Osgoode course (which also had some separate meeting time of its own), and the joint Jos-Osgoode virtual classroom. The adoption of this "tri-space" format (this maintenance of two separate regular courses at Jos and Osgoode) was necessitated by the need to avoid "the significant difficulties that would have been encountered in shepherding a single course through bureaucracies of [two] universities" in two distant and different countries. ${ }^{1}$

During September to October 2007, the two regular classes came together and integrated in real time most Fridays. On account of time differences, these joint sessions were held during the late mornings in Toronto and late afternoons in Jos). These web-based video conference sessions lasted between one-and-a-half and two hours (depending on how quickly internet connections could be established by the IT people at both ends, and how late it was at the Jos end.

At other times, students at both law schools were encouraged to utilize a discussion board (located within the human rights in Africa course's website) in order to continue conversations that arose from class discussions. As we shall soon see, the discussion board worked very well for the Osgoode students, but was, for time and access reasons, rarely accessed by the Jos students.

For most of the web-based video conference sessions, students at both the Jos and Osgoode ends were provided at least one joint reading that framed the issues for discussion in that session. These joint readings were selected by both of us from a much larger set of materials prepared for the human rights in Africa course by Professor Okafor and his research assistant over the preceding summer.

\footnotetext{
${ }^{1}$ See D. Harris, J. McLaren, W.W. Pue, S. Bronitt, and I. Holloway, “'Community without Propinquity' - Teaching Legal History Intercontinentally" (1999) 10 Legal Education Review 1, at 7.
} 
Discussions were invariably led off by either of us, who raised one main question after the other and encouraged active participation. Students and faculty participated enthusiastically at both ends, some more than others. The allotted time was usually insufficient to exhaust the high energy that such discussions always generated. We had to take care to ensure an equitable allocation of the available time between the Jos and Osgoode "teams" of students, and within each "team" as well. There were many more students at the Jos end (usually over 20) than at the Osgoode end (9 registered LLB and graduate students and 1 student observer from the University of Toronto).

The web-based conferencing sessions were almost always monitored by at least one IT person in each of the two physical classroom locations at Jos and Osgoode in order to ensure that the equipment functioned well and the internet video link was not disconnected. Additionally, the Osgoode IT person had the ability to monitor the conference from a remote connection, and even send messages to the Osgoode faculty and students via the video screen regarding any technical hitches. On a number of occasions, despite several successful tests in between sessions, the conference was in fact disconnected mid-stream and the IT teams at both ends had to work together to reconnect it.

The actual delivery of the transnational classroom course at the Osgoode end was not without its challenges, but was on the whole successful.

\section{B. The Project Conception/Design Process}

\section{Broad Objective}

The broad objective and ambition of the project was and continues to be to internationalize in-class discussions, enrich pedagogic experiences, encourage active and therefore more effective learning, challenge myths and mythologies, encourage critical reflection, and broaden the intellectual horizons, of students at both Osgoode and Jos.

\section{How the Idea Formed}

While the original project conception was basically Professor Okafor's idea, ${ }^{2}$ the actual development of the full and mature idea and the actual project design occurred collaboratively between us (the partner faculty members at Osgoode and Jos) and with the IT staff at both ends. It was important to us that both the South partner (Jos) and the North

\footnotetext{
${ }^{2}$ In turn, Okafor was inspired by the earlier efforts of Wes Pue of the University of British Columbia (and his collaborators in Canada and Australia), and Craig Scott of Osgoode (and before that UBC) to teach intercontinentally or transnationally. Pue and co had taught a text-based internet course in 1997, and Scott had taught a video-conference based course in the late 1990s and early 2000s, using regular phone lines.
} 
partner (Osgoode) participate actively and fully in the development of the idea from project design to completion, and thus have "ownership" of the project.

We wanted to do something that added real value to our respective courses at Jos and Osgoode (not simply something that added "bells and whistles" ${ }^{3}$ to them). In and of itself, the use of IT is not education! $!^{4}$ After much consultation, pondering of the advice of our IT collaborators, reflection, and trial and error, we settled on the use of internet-based videoconferencing that would avoid long distance phone charges; an internet-based discussion board; and a chat-room solution that could enable some research collaboration among our respective students outside the classroom. For technical reasons, we did not end up pursuing the third option during this first iteration of the virtual transnational classroom.

\section{Funding}

The project was co-funded by York University and the University of Jos. Seperate York Incentive and York Internationalization Grants were awarded to Professor Okafor, while a Visiting Professorship and a Comparative Research in Law and Political Economy (CLPE) Fellowship were awarded to Professor Dakas at Osgoode. Some financial assistance was provided by the Dean of Law at the University of Jos. Human resources and equipment were also provided by the University of Jos and Osgoode. Less conventionally, some funds were sourced from our own research and even personal budgets.

\section{Needs Assessment Mission}

In accordance with the underlying "active participation and ownership" model adopted by us for both this project and the broader program of which it is a part, Professor Okafor and his research assistant conducted a broader needs assessment mission to the Jos and other Nigerian universities in the summer of 2004. We were received well almost everywhere and the mood of the potential partners in Nigeria was largely enthusiastic. While we already knew a lot about these institutions and Nigeria, we still learnt a lot from this trip. One important such fact was that while all the universities we visited had made impressive strides in the development of their IT capacities, Jos was the clear leader in this regard. This and other factors led us (at the Osgoode end) to approach Jos to become our partners in this initial phase of this virtual transnational classroom project.

\section{Collaborative Construction of the IT Infrastructure}

Obiora Okafor was on site at the University of Jos to participate in the actual construction of the IT infrastructure that would make the virtual transnational classroom possible. We

\footnotetext{
${ }^{3}$ See D. Harris, et al, supra note 1 at 4.

${ }^{4} \mathrm{Ibid}$, at 4.
} 
both worked with the IT staff at Jos to ensure the success of the effort. Even after he departed from Jos, Okafor continued to be involved in the testing of the equipment. Dakas C.J. Dakas was actively involved via email and phone links in the discussions around the work on similar infrastructure at Osgoode.

\section{Why Teach in a Virtual Transnational Classroom, and Why this "Human Rights in Africa" Course in Particular?}

As we have already noted, in deciding to teach our respective courses transnationally and in choosing to do so via a virtual classroom, we were motivated by the desire to add real value to those courses, and not by any kind of desire to add "bells and whistles" or the socalled "wow factor". In our minds, a number of good reasons justify the deployment of this "transnational classroom" mode of learning within both partner courses. These are as follows:

The courses themselves were especially suited to Transnational teaching

Because of the well-known universalist vs. particularist tensions inherent in human rights thought and practice, and the socio-cultural and historical experiences and outlooks that significantly differentiate Canada from Nigeria, the two courses (on human rights in Africa and international human rights) were particularly well-suited to being offered in a transnational classroom setting.

Such a mode of delivery allowed IT resources to be creatively leveraged to bridge vast distances (physical and social) and thus broker cross-cultural communication, greater intercultural understanding, and a much deepened appreciation of the subject-matter of the course. As such, Osgoode students benefited as much as their counterparts in Jos from this richer, much broader, and much more challenging training in the human rights and African studies areas.

\section{Fostering a Level of Cross-Cultural Community}

This flows from the last point. ${ }^{5}$

Active Learning

The virtual transnational classroom mode allowed students at both schools to experience real life interchange and engagement with those who have historically been constructed as their "others", and to learn from each other in an active way. Rather than just telling them

${ }^{5}$ See D. Harris, et al, supra note 1 at 3. 
about each other's often different experiences, views, and approaches regarding human rights, the collaborating instructors led them to a place where they could discover this for themselves by, well, hearing it from the "horses mouth"! This active learning mode led to super-engaged classrooms at both ends.

\section{Debunking the myths about a uniformly simple and needy "Africa" and a monolithic "West"}

The real life interchange allowed students to begin to form a more nuanced, less uni-linear and complex view of the state of things (society, human rights talk and so on) in both "Africa" and "the West". For one, given the tendency to talk about the African continent almost exclusively in terms of its "lack" of this or that, the mere fact that the virtual transnational classroom could be done at all, was a bit of a lesson to many Osgoode students and other observers, and was a tiny reversal of a one-sided but dominant narrative. This then supported our pedagogic attempts to introduce a greater sense of nuance and complexity about the question of human rights in Africa. On the other hand, the tendency among some Nigerians to think of the Western approaches to human rights as relatively settled and uncontested was disturbed significantly by, among other things, the palpable differences in views among the Osgoode students. The debunking of this myth about the monolithic "West" served a similar pedagogic end as the discrediting of the myths about "Africa".

\section{Interactive Refinement and Reformulation of Previously Held Human Rights Ideas}

The interactive debunking of these various myths about each other's country or continent led in turn to the refinement and development of some student understandings of both "Africa" and "the West", and ultimately of various debates about the concept and practice of human rights.

\section{Much Lower Cost of Virtual Transnational Teaching}

Imagine what it would cost to fly all 60 or so Jos students to Osgoode and house them here in Toronto for three months, or vice versa? It cost a tiny fraction of this estimated amount to construct and operate the additional IT platform needed to teach the exact same group of students in a virtual classroom. So leveraging IT in this case provided substantial cost reduction advantages.

\section{Education-Equity Benefit}

As predicted by Wes Pue and his collaborators as far back as $1997,{ }^{6}$ the much lower cost of building community via a virtual transnational classroom provided a significant education

${ }^{6} \mathrm{Ibid}$, at 3. 
equity benefit in this case. The reduced cost leveled the playing field for all qualified students at Jos and Osgoode (instead of the few who could afford part of the costs of having to travel to Nigeria or Canada) to have the same opportunity to enjoy the benefits of being taught in this way.

\section{Challenges}

Notwithstanding the many advantages of teaching in the virtual transnational classroom mode and our strong commitment to the project, we confronted, and in almost all cases, overcame many challenges that militated against its technical and pedagogic success. These challenges are as follows:

The constant threat of strikes at the Nigerian end

Due to decades of an IMF/World Bank inspired massive funding cuts of higher education in Nigeria, Nigerian universities have taken a beating over the last 2 decades. As a result the academic and other staff unions in the universities are prone to launching strikes to try to force much needed improvements in that country's university sector. This has led to a degree of instability in the university system in Nigeria, and has led to many disruptions in the academic calendar; to the extent that it was often hard to estimate in advance when the school year would begin and end. The unpredictable danger was that the University of Jos could be on holidays at the time we planned to mount the joint course. We had to take this into consideration as we planned. To reduce this uncertainty, we decided that the partner course at the Jos end would be a Masters, rather than an undergraduate, course. Graduate courses are more flexibly scheduled in Nigeria.

\section{South-North resource asymmetries}

Although Jos was able to contribute significant financial and human resources to the project, much more of the funding was contributed by the York/Osgoode side of the partnership. The danger we tried to guard against was that $s /$ he who paid the piper often dictates the tune. Our participatory model of engagement mitigated this danger to an extent.

\section{Scheduling differences}

We had to work hard with the Dean's offices at both ends to align semesters, timing (a substantial time zone mismatch exists), and timetabling (in terms of the days on which the partner courses were taught). 


\section{Technical challenges}

As might be expected, the project was heavily IT reliant and dependent. We had the good fortune of having access to what are perhaps the best IT resources in a law school in each of our separate countries. Yet, a number of technical issues still presented problems that required much thought and work on the part of our IT teams to resolve. For example, "micing" (i.e. ensuring sufficient and efficient audio coverage of) the considerably more populous Jos class presented a challenge. Similarly, ensuring adequate video coverage of the entire Jos contingent with a stationary webcam mounted on a computer presented problems. We did not have the resources to deploy a more sophisticated system that would require the purchase and set up in Jos of an expensive Polycom video-conferencing system. As importantly, on one occasion the internet video-link to Jos went down and interrupted the joint session of the two classes. Most of these problems were quickly resolved, but we are in the process of seeking more funding to improve the equipment we use, and enhance the quality of the virtual classroom experience. Another problem was power outage at the Jos end. They solved this by deploying their standby generator each time we had a joint session.

\section{Constructing and using the virtual classroom is labor intensive}

The teaching and IT staff at both ends spent hundreds of hours well above and beyond what one would normally expect to put in if one were to plan for and teach a regular course. ${ }^{7}$ Other than for our personal satisfaction as teachers, there is as yet little incentive (e.g. real course release time or added pay), other then perhaps at promotion time, for faculty to undertake this kind of venture and to do the heavy extra work required. Even then, one can easily get promoted without teaching in this mode.

\section{The difficulty experienced by Jos students regarding their usage of the discussion board}

Jos students tended not to use the web-based discussion board perhaps because far fewer of them had access to internet connections at home, and most did not have the time to do so after class hours (most had families and worked full-time on the side while pursuing a full time degree program).

\section{Classroom culture issues}

Although known to be very outspoken people, the Nigerian students tended to defer just a little bit more to their instructors in terms of jumping into the conversation. As a result, the contributions of the instructors at the Jos end took up a bit more of class time than we had

\footnotetext{
${ }^{7}$ Ibid, at 29.
} 
wanted. While the instructor at the Osgoode end did lead most of the conversations, Osgoode students spoke a bit more frequently than the Jos students.

\section{E. The Factors that Contributed to the Success of the Project}

\section{Deep local knowledge of Nigeria and connections}

Concerning the Jos end Okafor's extensive and intensive "local knowledge" of the Nigerian and Jos local environments helped a great deal. He was from there, had lived most of his life there, had taught in a university there before coming to Canada, understood the "culture", knew much about what had to be done to succeed and had many strong human resource connections there. This made it easier for him to work successfully there and to actually get things done. Regarding the Osgoode end Dakas had studied in part in North America (at NYU), understood the culture well, and had many strong connections here. This had a similarly good effect.

Needs assessment mission sharpened and deepened knowledge of and connections to Nigerian society and the University of Jos

This is self-explanatory.

Our previous experience using IT in the classroom

Both of us have had years of experience in the leveraging of IT as a way of adding value to student learning experience. This helped a lot in the planning and execution of the project.

Impressive pre-existing IT infrastructure and human resources at both partner institutions

Now renowned as a leader in the application of IT to teaching and research in Canada, Osgoode is home to a remarkably strong IT unit that provided the electronic backbone of the project. Jos is, in our view, now widely regarded as the top such institution in Nigeria.

We remembered "the human"

Our insistence on the use of internet-based video-conferencing in addition to the textbased internet solutions was important to the success of the project. As Wes Pue and co have put it:

${ }^{8} \mathrm{lbid}$, at 5. 
"The intense, face-to-face, intellectual exchange possible in real as opposed to virtual communities has a quality about it which is impossible to replicate, even in endless hours spent pecking at a keyboard, firing meaning-packed electrons into the void. DCT [i.e. distance communication technology] is not human communication." ${ }^{9}$

Pue et. al would agree with us that text-based internet communication suffers far more from this deficiency than the kind of real-time internet-based video-conferences that we utilized in this project.

Cooperation and dedication of the Osgoode/York and Jos senior administration and the IT staff

This is self-explanatory.

Collaborative development of the project

This helped us anticipate and avoid/ameliorate bottlenecks and serious problems that would have frustrated our efforts in the end. For example, we avoided the use of analog phone lines in Jos - something that had looked like a great idea from the Osgoode end. We also avoided the use of an undergraduate course that would have been less flexible in terms of scheduling and semester alignment.

\section{Funding}

This is self-explanatory.

\section{Student Receptiveness}

Students were quite engaged and participated very actively on the whole.

\section{F. Next Steps}

Over the next few months and years, it is proposed to deepen and expand the project to include a student collaborative research component, an internship program, more faculty exchanges, and more universities in Nigeria (and possibly Canada). As the relative paucity of funding has been a major constraint to the enhancement of the project, effort is being made to reach out to possible major funders both in Canada and Nigeria.

${ }^{9}$ Ibid. 